\title{
The use of artificial intelligence and information technology in the training and professional activities of lawyers
}

By

Dr.Tamara D. Bogdanova

Associate Professor, Department of Civil Law Disciplines

Volgograd Institute of Management - a branch of the Russian Academy of National Economy and Public Administration under the President of the Russian Federation, Volgograd, Russian Federation.

Correspondence: chemisuli@mail.ru

\author{
Dr.Svetlana S. Simonova
}

Associate Professor, Department of Criminal Law Disciplines

Volgograd Institute of Management - a branch of the Russian Academy of

National Economy and Public Administration under the President of the Russian Federation, Volgograd, Russian Federation.

Correspondence: simonova.ss@mail.ru 


\begin{abstract}
The introduction of innovative technologies in the training of a future specialist is an indispensable element in forming the foundations of professionalism. A new approach to the educational process is a prerequisite for modern higher education. Currently, the literature uses several concepts that describe knowledge, abilities, skills, experience working with the information technology of a modern specialist - "computer literacy", "ICT competence", "information culture". In connection with the specifics of the legal profession, the use of artificial intelligence and information technology in the process of law students obtaining is of particular relevance. Also relevant is the problem of using information technology in the professional activities of lawyers. The aim of the article is to analyze the possibilities of innovative teaching methods for future lawyers and the use of information technology in professional activities.
\end{abstract}

Keywords Information technology, artificial intelligence, e-justice, informatization, digitalization of education. 


\section{Introduction}

The rapid development and implementation of information and communication technologies in the field of law have an impact on the development of legal education. A competency-based approach to education allows you to prepare a specialist who is able to adapt to changing conditions and demonstrate high efficiency in work. The role of information and communication competence as the basis of self-education and self-development throughout life is growing, since the necessary attribute of the professional suitability of a lawyer in the modern information society is the ability to use information technologies, their tools and methodology for working with information. (Abdusalamov, Medzhikova, 2017).

Every year, lawyers use technology more and more often in their activities. Reference legal systems, judicial filing cabinets, electronic justice, electronic registers, designers of contracts and other documents, various search engines (for example, patent search), data storage and storage systems are developing everywhere. On the one hand, these technologies allow you to automate the work of a lawyer, on the other hand, a lawyer must be able to navigate them, and use in their activities those that will facilitate his work. 
Today, our society, with its changes in all spheres and social institutions, is faced with acute problems in training future specialists. Education at universities should provide training for a competent specialist with a broad scientific outlook, able to use the latest achievements of science, technology and practice, a specialist who is able to work with people, make the right decisions, both in typical and non-standard situations. (Skorobogatova, Melihova, Datsko, 2017) Such skills are, of course, necessary for students receiving a law degree. As a result, students should develop the skills to work with modern information technologies in legal activity, necessary when studying the disciplines of the professional cycle. This is especially important when considering issues related to the study of the basic concepts, principles, methods of implementing information processes in the legal sphere.

In this regard, the task of teachers is to determine the optimal means and methods of training that positively affect the quality of training of future lawyers. Teachers should attract students to work with special programs, teach them to understand all their diversity and select the ones that are suitable for solving specific issues.

As lawyers increasingly began to use digital technologies both when working with clients and when processing information, an increasing number of law schools include technology training in 
their curricula. At the same time, the prospect of the emergence of a large number of lawyers with digital skills reinforces the need to develop new technological tools and methods used in the training of lawyers that meet changing human needs. In this regard, when training future lawyers, it seems important to combine technological training with teaching social approaches that are oriented to a person. (Jackson, 2016)

With the development of technology for the search, processing and storage of information, the work of specialists, including in the field of jurisprudence, is changing qualitatively. At the same time, artificial intelligence is already reflected in the practical activities of lawyers. (Hilt, 2017) This does not mean at all that lawyers will be supplanted by artificial intelligence (as evidenced by the competition between lawyers and artificial intelligence). It seems that artificial intelligence will be able to perform typical tasks and prepare documents. This will free up the time necessary for a lawyer to solve more complex problems that require high concentration and the ability to evaluate moral categories.

Legal technologies (digital solutions for the provision of legal services) have become a significant reason for competition among participants in the legal services market. (Hongdao, Bibi, Khan, Ardito, Khaskheli, 2019) According to forecasts, in the coming 
Tamara D. \& Svetlana S. عدد خاص بالمؤتمر الدولى السنوى العشرون

years, progress in the development of information technology and new business methods (in connection with the digitalization of the economy) will challenge the traditionally conservative legal profession. (Waye, Verreynne, Knowler, 2018).

\section{Materials and Methods}

The methodological basis of the study was systemic and integrated approaches. The research was based on search and expert approaches, as well as the fundamental ideas of domestic and foreign authors, determining the role and place of new information technologies in the system of higher professional education. The authors also use methods of theoretical research (literature review and generalization of advanced pedagogical experience and empirical research), analysis of educational programs.

\section{Literature Review}

The modern rapidly growing information field entails the need for computerization of humanitarian disciplines, in particular legal ones. Although in the works of researchers in the field of pedagogy in legal education (A. S. Batyshev, N. R. Bityanova, I. V. Biochinsky, A. V. Budanov, I. V. Gorlinsky, V. P. Davydov, G. P. Davydov, V. G. Kolyukhov, N. S. Kravchuk, A. D. Lazukin, I. A. Latkova, V. M. Obukhov, A. V. Pishchelko, V. I. Postoev, M. P. 
Tamara D. \& Svetlana S. عدد خاص بالمؤتمر الدولى السنوى العشرون

Sturova, V.P. Trubochkin, N.A. Tyugaev, I.E. Farber, A.A. Fedotov, and others) the problem of informatization has been outlined, but it has not received its further development.

The views of domestic and foreign researchers on the informatization of society reveal the many risks of the functioning of the information environment, but in no way reduce the importance of information technology in improving state institutions. (Khrapenko, 2019)

It should be noted that every year the boundaries of discussions on the interaction of jurisprudence and information technology are becoming wider. (Simpson, 2017)

In recent years, pedagogical theory and practice have developed various areas of research in computerization and computerization in higher education. The problem of digitalization of legal education is studied from different angles. Thus, a number of scientists are considering the integration of the iPad into professional legal education as an example of following the global trend towards mobile learning. (Brennan, Kennedy, 2015). Research by Professor Osborne on the status of legal education in the context of the application of information technology in training seems relevant. (Osborne, 2016). 
Currently, research by a number of scientists is devoted to the development of empirical methods for identifying the relationships and structure of the administrative law enforcement process based on the analysis of semi-structured data. (Metsker, Trofimov, Sikorsky, Kovalchuk, 2019)

The actual issue in the field of digitalization of legal education and the use of information technology in the activities of lawyers remains automatic processing of legal texts. Researchers note that the legal language is specific and in the process of digitalization it is not always possible to accurately convey the meaning of legal quotes, formulas and symbols. (Nazarenko, Wyner, 2017)

It seems to us reasonable the point of view of a number of authors, according to which, in the process of changing technologies and their integration into the legal sphere, jurisprudence itself will conceptually change. (Kathrani, 2017).

\section{Results}

The idea of artificial legal intelligence stems from the previous wave of artificial intelligence, which was then called law. It was based on an algorithmic understanding of law, in which logic was considered the only component of the correct legal argument. However, as Oliver Wendell Holmes noted, the life of law is 
experience, not just logic. Machine learning, which defines the current wave of artificial intelligence, is based on the experience of data-driven machines. As a result, artificial legal intelligence can be much more successful in terms of predicting the content of positive law. (Hildebrandt, 2018)

To date, the thesis of the complete replacement of lawyers by robots is unreasonable and premature. It is impossible to fully trust artificial intelligence to solve legal issues. Analysis of the opinions of many scientists allows us to conclude that creating artificial intelligence, its creators do not know what will turn out in the end. An example is the artificial intelligence "Norman", which thinks like a psychopath, and in any picture from the Rorschach test he sees death scenes.

Currently, the robot can replace a lawyer only when performing programmed routine tasks, such as drawing up simple templates of contracts, claims, searching for case law materials, compiling analytical information, transferring documents to court, etc. (Khabibullina, Seleckaya, Shpagonov, 2019) But at the same time, artificial intelligence cannot compete with humans in the complex analysis of a specific problem; in assessing the fairness and honesty of the person who filed the application. The field of law cannot be translated into a programming language due to the 
Tamara D. \& Svetlana S. عدد خاص بالمؤتمر الدولى السنوى العشرون

variety of terms, categories and differences in their interpretation. The proof of the above is the fact that it is very difficult to create smart contracts. Since it is practically impossible to write in the form of program code all the possible conditions of the contract. In each specific situation, there are many features that are virtually impossible to consider when writing a program.

High-quality professional legal activity is possible only with the participation of a professional lawyer with experience in this field. It is difficult to imagine a robot that performs the functions of a representative in court or a robot scientist (lawyer). Today, artificial intelligence can perform almost any ordinary mechanical work with much greater productivity, and the activities of a lawyer are aimed primarily at solving more complex intellectual problems. It should be noted that the active use of artificial intelligence and information technology in law can reduce the cost of legal services, which will lead to the democratization of the legal profession. (Yoon, 2016)

Despite the fact that it is impossible to completely replace a lawyer with artificial intelligence, it is necessary to automate the work of a lawyer as much as possible. There are various programs and systems for this. 
It is no secret that lawyers actively use various reference and legal systems (Lexis, Consultant plus, Guarantor, etc.) in their work, in which you can find the whole array of legislation of the state where this system is used, international acts, judicial practice, other law enforcement practices, as well as legislative comments, scientific articles, document forms, and much more. All information is systematized. Each document is provided with the necessary explanations. In addition, reference and legal systems provide many interesting features (comparing documents, information about a document, saving in bookmarks, etc.).

In addition to legal reference systems, there are also judicial filing cabinets that contain decisions of courts of all instances. It is enough to enter the data of the case (for example, number), and we will be given the whole set of court documents. There are services offering to find selections of the most significant cases on a specific legal issue (for example, the American Ravel Law service).

In the work of a lawyer it is very important to systematize the processes. It is necessary to set goals and achieve their fulfillment in strictly established terms. For large law firms, it is important to delegate tasks. For these purposes, appropriate services (Notion, Tilda, etc.) are perfectly suitable. 
To automate the process of working with clients, numerous chat bots are created that can answer the initial questions of customers. By the time the client gets to the lawyer, the lawyer will know what kind of questions the client is interested in.

Nowadays, servers of online consulting, quick compilation and automatic filling of documents, etc. are widely developed.

Separately, we can say about applications - document designers. By setting certain parameters, we can get any document that interests us. Of course, such a document will be fairly standard. An important role will be played by a lawyer who can fill such an agreement with the necessary elements in order to protect the interests of counterparties under the agreement to the maximum.

Very convenient servers for checking counterparties. The lawyer enters the name of the organization and its registration number and sees all the information about the company, the availability of court cases, the presence of debts, fines, administrative penalties. Thanks to these programs, one can evaluate the solvency and reliability of the counterparty.

In various areas of jurisprudence specific legaltex are used. Thus, advanced developments in the field of patent search and analytics use patent services around the world, which allow finding similar inventions, utility models, industrial designs, trademarks, not only in the territory of their jurisdiction, but also in other states. 
In the field of copyright, systems are created that allow to donate works of science, literature and art from the comfort of home, in one click. For example, in Russia there is an electronic copyright protection service Ireg. Registration in it allows you to deposit any number of copyright objects and receive electronic certificates for them within five minutes. That will allow to form the evidence base and use it in case of copyright infringement.

Criminologists use electronic file cabinets that contain information about criminals; forensic experts are also actively using various 3-D modeling systems. When investigating crimes and searching for criminals, it is very important to correctly compose the identikit of the wanted person. Modern programs for the compilation of photobots allow the most detailed designation of facial features of a criminal obtained from the words of witnesses or victims. Such wanted portraits (orientations) make it possible to identify wanted persons to a wide number of citizens.

Currently, there are technologies in the search for lawyers working in a certain field, taking into account the cost of their services. For example, Legal Space or Platforma (looking for lawyers working on the "no win no fee" model). Such a platform helps not only clients, but also lawyers who are looking for partners in different cities. (Mironova, Bogdanova, Simonova, 2019)

These provisions should also be taken into account in the training of future lawyers. It seems that in the framework of 
preparing students for a separate discipline, the teacher should additionally talk about the possibilities of applying the corresponding LegalTex. So, during the study by students of the Volgograd Institute of Management, a branch of the RANEPA, the course "Intellectual Property Law", they get acquainted with existing patent search systems (including free search on the Internet). The teacher tells students about the possibility of electronic interaction with the Federal Institute of Industrial Property through the portal "State Services" and also through the service "Online Patent". When studying the topic "Copyright", it talks about the systems of depositing copyright existing in Russia and the world, about the possibility of blocking sites, etc.

\section{Discussion}

Information technology by its nature has enormous potential, which, combined with carefully selected pedagogical technologies, contribute to improving the quality of student training, in particular the successful formation of the necessary professional competencies. The insufficient use of software products for training future lawyers, the partial development of uniform pedagogical requirements and their rapid obsolescence in the framework of technological progress, entails the need for continuous improvement of the teaching staff using the latest achievements and information technologies. 
Currently, students studying at law schools in higher educational institutions are gaining skills in using computer technology in the following actions: in the preparation of judicial and other official documents, information support and decision support, organization and monitoring of work, reporting; when posting on the Internet on the court's website information on pending cases, as well as texts of judicial acts; when compiling and posting information on court activities in public networks and on the court's official website on the Internet.

Nevertheless, since information technologies themselves are actively developing, it is necessary to constantly expand and improve not only the theoretical base, which is the main part of students' mastering of the studied disciplines, but also practical skills in the field of information technology. In the formation of ICT competency, the necessary condition is the use of personal computers, multimedia technologies and applied software products in the educational process. Such multimedia qualities as interactivity, flexibility, generalization of various types of visual educational information, allow you to take into account the individual characteristics of students and increase motivation, which determines the effectiveness and productivity of their use.

At the same time, in our opinion, a lawyer is not required to be a specialist in LegalTech, but he must be aware of them and be able 
to apply in their activities those that will help him simplify and systematize his activities.

\section{Conclusions}

The formation of an "information culture" as a socially significant basis for professional activity in the information environment is associated with personality manifestations such as the search for the individual meaning of information activity and a humanistic value orientation, free and responsible choice of behavior and position in relation to processes and phenomena of informational reality, conscious and creative the nature of the goals and methods of information activities, as well as the most complete implementation of the needs of such activities th, abilities and aspirations of the individual in the interest of its own development. (Abdusalamov, Medzhikova, 2017)

A modern student not only quickly and easily learns the Internet, mobile technologies, reference and legal systems, but also uses them both during study and in his free time. And this feature must be actively used. The educational process should be built in such a way that the student not only mastered the practical skills of working with computer technology, but also received knowledge in the field of legal support of information activities. In the future, he should have the basic skills and professional skills of working with 
legal information: search, selection, assessment, use. There is no doubt that, given the requirements of the labor market, in addition to legal skills, lawyers should also develop their knowledge of information technology. (Golenko, Siber, 2019). Thanks to the development of new information technologies, lawyers will be able to work more efficiently, deepen and expand their professional competencies. (Alarie, Niblett, Yoon, 2018).

\section{References}

Abdusalamov R.A., Medzhidova Kh.S. , 2017. Building ICT competencies for future lawyers in continuing education, Pedagogical Journal, Vol. 7. Is. 6A, pp.118-125.

Alarie, B., Niblett, A., Yoon, A.H., 2018. How artificial intelligence will affect the practice of law. University of Toronto Law Journal, No 68, pp.106-124.

Brennan, G., Kennedy, C., 2015. Eating the apple: integration of the ipad into irish professional legal education. 8th International Conference of Education, Research and Innovation (ICERI), Seville, Spain, pp. 4856-4863.

Golenko, D., Siber, L. ,2018. Information Literacy of Lawyers in Their Working Environment. Communications in Computer and Information Science, No 810, pp. 78-86. 
Hildebrandt, M., 2018. University of Toronto Law Journal, No 68, pp. 12-35.

Hilt, K., 2017. What does the future hold for the law librarian in the advent of artificial intelligence? | [Que réserve l'avenir pour le bibliothécaire de droit avec la venue de l'intelligence artificielle?]. Canadian Journal of Information and Library Science, No 41(3), pp. 211-227.

Hongdao, Q., Bibi, S., Khan, A., Ardito, L., Khaskheli, M.B., 2019. Legal technologies in action: The future of the legal market in light of disruptive innovations. Sustainability (Switzerland), No 11(4), P.1015.

Jackson, D., 2016. Human-centered legal tech: integrating design in legal education. Law teacher, Volume: 50 Issue: 1 Special Issue. pp. 82-97.

Kathrani, P., 2017. An 'existential' shift? Technology and some questions for the legal profession. Legal Ethics/ No 20(1), pp. 144-146.

Khabibullina, A. Sh./ Seleckaya, S.B., Shpagonov, A.N.,2019. The problems of robotisation of legal profession. Revista genero \& direito, Volume 8, Issue 6, pp. 397-405. 
Khrapenko, O., 2019. Use of the "electronic court" system in future lawyers training. Information technologies and learning tools. Volume 70, Issue 2, pp. 155-164.

Metsker, O., Trofimov, E., Sikorsky, S ., Kovalchuk, S., 2019. Text and Data Mining Techniques in Judgment Open Data Analysis for Administrative Practice Control. Electronic governance and open society: challenges in eurasia, egose 2018. Book series: Communications in Computer and Information Science, Volume 947, pp. 169-180.

Mironova, S., Bogdanova, T., Simonova, S., 2019. The introduction of digital technologies in the educational process of training lawyers. SHS Web of Conferences Volume 69, 00079. pp. $1-6$.

Nazarenko, A., Wyner, A., 2017. Legal NLP Introduction. Traitement automatique des langues, Volume 58, Issue 2, pp. 7-19.

Osborne, C.L., 2016. The state of legal research education: A survey of first-year legal research programs, or "why Johnny and Jane cannot research". Law Library Journal, No108(3), pp. 403-425. 
Simpson, B., 2017. Special issue: disrupting technology, disruptive norms: the role of law in a digital world. Information and Communications Technology Law, No 26(1), pp. 1-5.

Skorobogatova, A., Melihova, I., Datsko, N., 2017. Innovative methods in teaching of the discipline 'fair employment practices law' for professional training of future lawyers. 10Th international conference of education, research and innovation (iceri2017), book serie ICERI Proceedings, pp. 1375-1380.

Waye, V., Verreynne, M.-L., Knowler, J. 2018. Innovation in the australian legal profession. International Journal of the Legal Profession, No 25(2), pp. 213-242.

Yoon, A.H., 2016. Focus feature: Artificial intelligence, big data, and the future of law. University of Toronto Law Journal, No 66(4), pp. 456-471. 